\title{
Reactive oxygen metabolites and the human
} myocardium

\author{
CHRISTOPHER J BURRELL, DAVID R BLAKE \\ From the Cardiac and Rheumatology Departments, The London Hospital, London
}

Thrombolytic treatment in acute myocardial infarction achieves coronary patency in most patients. ${ }^{1}$ Mortality in groups treated early after the onset of symptoms is significantly reduced, ${ }^{2-4}$ but left ventricular function does not always improve. Myocardial necrosis during the period of vessel occlusion is partly responsible for the irreversible ventricular impairment that occurs even when the vessel is re-opened. In the dog the expanding area of myocardial necrosis induced by experimental coronary occlusion is surrounded by a potentially viable ischaemic zone. ${ }^{6}$ But viable ischaemic cells can be irreversibly damaged when coronary flow is reestablished. During reperfusion, molecular oxygen is converted to oxygen metabolites, which are toxic and can promote further tissue injury. In this way, reoxygenation of the myocardium may itself result in secondary deterioration in myocardial function-the "oxygen paradox". 7 In animal models the extent of injury is reliably reduced and residual myocardial function appreciably improved by agents that either suppress the generation of oxygen derived free radicals or inhibit the damaging effects that these reactive oxygen metabolites produce. ${ }^{8}$

Direct evidence of injury by free radicals has yet to be shown in the human heart, but many studies of other mammals have linked reactive oxygen metabolites with myocardial injury. Many workers conclude from these studies that interventions directed against free radicals will improve myocardial function after thrombolysis for acute infarction and in other forms of myocardial revascularisation (coronary bypass graft surgery and coronary angioplasty) and during cardiac transplantation. Appreciation of such studies depends on an understanding of some simple biochemistry.

Requests for reprints to Professor David R Blake, Department of Rheumatology, The London Hospital, Whitechapel, London E1 1BB.

\section{BIOCHEMISTRY OF OXYGEN AND ITS FREE} RADICALS

A free radical is an atom, ion, or molecule with one or more unpaired electrons. This configuration leads to an increased reactivity with other molecules. The amount of reactivity depends on the ease with which a species can accept electrons (is reduced) or donate them (is oxidised).

During aerobic metabolism molecular oxygen $\left(\mathrm{O}_{2}\right)$ acts as the terminal electron acceptor and undergoes stepwise reduction to water. Oxygen is a bi-radical: it has two unpaired electrons in separate, parallel orbits both spinning in the same direction. ${ }^{9}$ Non-radical species have paired electrons spinning in opposite directions. One of these must spin invert before both can be accepted by oxygen. This process can occur, but limits the reactivity of molecular oxygen, which preferentially accepts electrons one at a time (univalent reduction). The univalent reduction of oxygen produces the superoxide anion radical $\left(\mathrm{O}_{2}{ }^{-}\right)$.

$$
\text { Equation (1) } \mathrm{O}_{2}+\mathrm{e}^{--} \rightarrow \mathrm{O}_{2}^{--}
$$

In this equation, the dot $(\cdot)$ represents an unpaired electron and signifies a free radical.

The superoxide anion is comparatively unreactive. It has a very short half life and its solubility in lipids is low. These properties limit its capacity to diffuse away from its site of generation and to affect cell membranes. In an ischaemic environment with acid $\mathrm{pH}$, the anion will become protonated forming the more reactive perhydroxyl radical $\left(\mathrm{HO}_{2}\right)^{-}$. Because this radical is uncharged, and therefore more lipophilic, it can damage cell membranes.

Because of its electronic configuration the superoxide anion can act both as a reducing agent and an oxidising agent. It can reduce transition metal ions, such as ferric $\left(\mathrm{Fe}^{3+}\right)$ and cupric $\left(\mathrm{Cu}^{2+}\right)$ ions, thereby enabling them to act as catalysts in other free radical reactions.

Further univalent reduction of the superoxide anion yields a non-radical species $\left(\mathrm{O}_{2}^{2-}\right)$, which exists 
at physiological $\mathrm{pH}$ in its protonated form, hydrogen peroxide $\left(\mathrm{H}_{2} \mathrm{O}_{2}\right)$. This is less reactive, longer lived, and more lipophilic than the superoxide anion radical $\left(\mathrm{O}_{2}{ }^{-}\right)$. It can diffuse considerable distances from its site of generation and will cross cell membranes. Damage can occur at distant sites via its reduction to the hydroxyl radical ( $\mathrm{OH} \cdot)^{\text {. It }}$ is this reduction reaction (the Fenton reaction) which requires a transition metal ion, such as the ferrous ion $\left(\mathrm{Fe}^{2+}\right)$ as catalyst. ${ }^{10}$

$$
\text { Equation (2) } \mathrm{H}_{2} \mathrm{O}_{2}+\mathrm{Fe}^{2+} \rightarrow \mathrm{OH}+\mathrm{OH}^{-}+\mathrm{Fe}^{3+}
$$

The hydroxyl radical ( $\mathrm{OH} \cdot)$ is extremely reactive and has a very short half life. It will react rapidly with most biological substrates, but its damaging effects are localised-it is only likely to modify other molecules within 1-5 molecular diameters of its site of production. ${ }^{11}$

Radical reactions tend to self perpetuate, producing both the less reactive and the more reactive species. The process terminates only when two radicals collide with each other and interact. Toxicity is affected by the availability of transition metal ions, which catalyse production of the highly reactive hydroxyl ion. It has even been suggested that iron deficiency may protect against myocardial damage in coronary disease. ${ }^{12}$

\section{BIOLOGICAL SOURCES OF FREE RADICALS}

While four-electron transfer (tetravalent) reduction of molecular oxygen does occur naturally, and is usually catalysed by the mitochondrial enzyme cytochrome oxidase, several other enzyme systems can reduce molecular oxygen in univalent steps, as described above, and therefore act as sources of reactive oxygen metabolites.

\section{Neutrophils: the respiratory burst}

When neutrophils, and other white cell types, are activated two enzyme systems generating free radicals are stimulated: these are the plasma membrane associated nicotinamide adenine dinucleotide phosphate (reduced form) (NAD(P)H) oxidase system and the lysosomally based halide/ myeloperoxidase system. ${ }^{13}$ This results in formation of superoxide anion radicals $\left(\mathrm{O}_{2}{ }^{-}\right)$, hydrogen peroxide $\left(\mathrm{H}_{2} \mathrm{O}_{2}\right)$, hydroxyl ion $(\mathrm{OH} \cdot)$, and hypochlorous acid (HOCl). These can be detected in the extracellular environment and can promote tissue damage. Activation of white cells occurs in response to many stimuli. These may be particulate (such as bacteria) or non-particulate (such as the protein products of an acute inflammatory reaction-complement, kinin, and cytokines). Neutrophil generation of reactive oxygen metabolites may therefore be relevant to both defence against bacterial infection and to processes involving inflammatory reactions, such as acute myocardial infarction-when neutro- phils are indeed recruited to the infarct site.

Another consequence of neutrophil activation is the release of proteolytic enzymes, such as elastase, which may enhance tissue damage. Oxygen radicals may indirectly increase elastase activity, because alpha-1-protease inhibitor, which is normally responsible for elastase inactivation, is itself susceptible to oxidative attack.

\section{Endothelial cells}

In the capillary endothelial cell (and at other biological sites), the cytosolic enzyme xanthine oxidase is normally present in a dehydrogenase form, using nicotinamide adenine dinucleotide $\left(\mathrm{NAD}^{+}\right)$as an electron acceptor, for the conversion of the purines, hypoxanthine and xanthine, to uric acid. During ischaemia, the dehydrogenase form is converted to the true oxidase form, which uses oxygen, instead of $\mathrm{NAD}^{+}$, as electron acceptor. On reperfusion of ischaemic tissue, the delivered oxygen can be reduced by this system, producing superoxide anion radical and hydrogen peroxide. ${ }^{14}$

In the myocardium the xanthine oxidase system could be an important source of free radicals, ${ }^{15}$ but recent work suggesting that proteolytic conversion into the true oxidase form is rather slow in the heart ${ }^{16}$ makes this less likely.

\section{Other sources of free radicals}

In addition to the respiratory burst of neutrophils and the cytosolic xanthine oxidase/dehydrogenase system, other important intracellular sources of free radical production include the mitochondria, the endoplasmic reticulum, and the peroxisome.

During ischaemia, components of the mitochondrial electron transport chain become reduced. On re-oxygenation, single electron reduction of oxygen is then more likely and results in increased superoxide production. In addition, enzyme catalysed demethylation and hydroxylation, which are usually coupled to the reduction of $\mathrm{NAD}(\mathrm{P}) \mathrm{H}$, may become uncoupled after transient ischaemia. Oxygen is then reduced instead of $\mathrm{NAD}(\mathbf{P}) \mathrm{H}$, with resultant superoxide generation. ${ }^{17}$

Finally, free radicals may be generated in association with the arachidonic acid cascade. It may be relevant that during ischaemia, activation of phospholipase increases the release of arachidonate. ${ }^{18}$

It can be seen that normal cellular metabolism can result in free radical generation and that these intracellular sources may be enhanced during a short lived ischaemic episode. During such adverse conditions normal tissue protection against auto-oxidative tissue damage may be impaired.

BIOLOGICAL PROTECTION AGAINST DAMAGE BY FREE RADICALS

Intracellular superoxide concentrations are kept very 
low by the spontaneous "dismutation" of superoxide anion radical to hydrogen peroxide. This reaction may be catalysed by the enzyme superoxide dismutase (SOD).

$$
\text { Equation (3) } \mathrm{O}_{2}^{-}+\mathrm{O}_{2}^{-}+2 \mathrm{H}^{+} \stackrel{\mathrm{SOD}}{\longrightarrow} \mathrm{H}_{2} \mathrm{O}_{2}+\mathrm{O}_{2}
$$

Intracellular hydrogen peroxide concentrations are also kept low by its divalent reduction to water, catalysed by the seleno enzyme glutathione peroxidase, and, when hydrogen peroxide concentrations are raised, by the haem centered enzyme catalase. Extracellular concentrations of all these enzymes are low.

Enzymic removal of the hydroxyl radical is precluded by its extreme reactivity. Protection against this radical is dependent on the prevention of its generation or on its scavenging by antioxidants. Scavengers of free radicals are molecules which react with radicals, often producing another radical compound. Antioxidants react to produce less harmful radical species. Naturally occurring antioxidants include $\alpha$ tocopherol (vitamin E), ascorbate (vitamin C), thiols, selenium, and zinc.

Free iron concentrations are kept low by binding to proteins. Intracellular iron is bound to ferritin, and extracellular iron to transferrin and neutrophil derived lactoferrin.

Such compartmentalisation of metal ions is important in reducing random generation of hydroxyl radicals. Hypoxia (by reducing the $\mathrm{pH}$ ) and xanthine oxidase (by generating the reducing agent superioxide anion radical) may cause decompartmentalisation, and therefore promote metal catalysed oxidative tissue injury. ${ }^{19}$

\section{POTENTIAL MECHANISMS OF TISSUE INJURY MEDIATED BY FREE RADICALS}

Polyunsaturated fatty acids are found in all cell membranes and they are particularly susceptible to oxidation by free radicals. Rearrangement of the double bond (diene conjugation) gives rise to the formation of lipid peroxides, which in the presence of oxygen participate in an autocatalytic chain reaction. The products of this reaction have a wide range of cytotoxic and pro-inflammatory effects. Protein damage, enzyme release, and oxidation of extracellular lipoproteins may lead to further damaging effects, with spread to adjacent cells. ${ }^{20}$

INVESTIGATION OF FREE RADICAL MECHANISMS IN THE HEART

Clinical investigation is hampered by the difficulty in directly measuring the ephemeral free radical, especially in complex biological systems. ${ }^{21}$ Specific tissue damage caused by free radicals may be easier to measure. In particular, free radical damage of lipids and proteins can be assessed.

For example, free radical activity and the extent of tissue damage are related semiquantitatively to the amount of lipid peroxidation. This may be estimated by measuring loss of substrate, uptake of oxygen, diene conjugation, or alkane production. However, the most frequently used assay of lipid peroxidation, the thiobarbituric acid test, has considerable limitations in vivo. It lacks specificity, and doubt remains about the interpretation of results. ${ }^{22}$ Nevertheless, while each method has limitations, where several different methods have been compared there is generally a good correlation.

But the finding of lipid peroxidation in association with a particular disease state cannot be used to implicate free radical damage as a direct cause of the disease process, because tissues damaged by any mechanism will peroxidise (go rancid) more rapidly than healthy tissue. ${ }^{23}$

Free radical damage to proteins, and especially immunoglobulins, may also be measured, and recently the technique of electron-spin resonance spectroscopy has permitted identification of a free radical in whole tissue, by measurement of the magnetic moment resulting from the spin of its unpaired electron. ${ }^{24}$

In anaesthetised dogs regional myocardial ischaemia may be induced by ligation of a coronary artery. In these circumstances, concentrations of malondialdehyde (a product of lipid peroxidation) in the coronary venous blood gradually increase with time, reaching a peak at three hours. At the same time, electron-spin resonance spectroscopy of the ischaemic myocardium shows oxygen free radical production. There is depletion of naturally occurring antioxidants, such as alpha-tocopherol (vitamin E) and ascorbate (vitamin C), and of the enzyme scavengers superoxide dismutase, catalase, and the selenoenzyme glutathione peroxidase..$^{25}$

Several recent studies that used a xanthine oxidase/purine system to generate free radicals have confirmed, at least in the rat, the detrimental effects of free radicals on the normal myocardium. There is both reduced contractility ${ }^{26}$ and ultrastructural change, including swelling of myocytes and endothelial cells, with intracellular disruption. ${ }^{27}$ Superoxide dismutase and catalase, ${ }^{27}$ and antioxidants ${ }^{28}$ have considerable cardioprotective effects.

In animal models, agents that scavenge free radicals may reduce ischaemic injury. Pre-treatment with allopurinol reduces the calculated ischaemic volume below mid-left anterior descending artery ligation, ${ }^{29}$ and inhibits ischaemic (and reperfusioninduced) arrhythmias. ${ }^{15} 3031$ While the mechanism of benefit may be a reduction in free radical generation via inhibition of xanthine oxidase, allopurinol is also 
a direct scavenger of the hydroxyl radical. However, a vasodilator effect, and maintenance of the nucleotide pool by allopurinol, have also been suggested as possible cardioprotective mechanisms.

Many groups using a range of animal reperfusion models have shown highly significant cardioprotective effects by free radical scavengers such as mannitol (an hydroxyl radical scavenger), scavenging enzymes, antioxidants, and iron chelators such as desferrioxamine. Benefit has been assessed mainly in terms of reduction in infarct size and an improvement in ventricular function in treated as compared with untreated control groups. Appreciable reduction of infarct size was shown by histological and autoradiological techniques, ${ }^{32-34}$ which estimate the percentage of the "at risk" myocardium that becomes infarcted, and by reduction in creatinine kinase release. $^{3536}$ Striking improvement in ventricular function, assessed by preservation of developed pressure (dP) and $\mathrm{dP} / \mathrm{dt} \max$, reduction in end diastolic pressure, and preservation of systolic wall thickening, are also seen in treated groups ${ }^{37-39}$ Furthermore, the beneficial effects of agents that oppose free radicals are associated with a reduction in free radical production measured directly by electron-spin resonance spectroscopy and indirectly by lipid peroxidation. At the same time, energy stores are increased in the treated, reperfused myocardium. ${ }^{36}$

The studies showing most improvement were of treatment started before the onset of ischaemia. In clinical situations if treatment is started later during the ischaemic period immediately before reperfusion it may be less beneficial. Furthermore, some studies suggest that intervention directed against free radicals may only delay rather than prevent myocyte necrosis. ${ }^{34}$

\section{CONCLUSION}

The complexity of free radical generation and interaction provides several potential therapeutic targets; and a combined approach that uses xanthine oxidase inhibitors, antioxidants, radical scavengers, and metal chelators is most likely to reduce myocardial reperfusion injury mediated by free radicals in man. Xanthine oxidase inhibitors, allopurinol and oxypurinol, and antioxidants are available. Both recombinant human superoxide dismutase and selenium-based glutathione peroxidase analogues are being developed, and chelators with greater specificity for iron, and which lack the ocular toxicity of desferrioxamine, are being evaluated in animals.

Although free radicals have been implicated in many injurious processes, ${ }^{82021}$ it should be borne in mind that they may also have a beneficial role. Reactive oxygen metabolites are known to be impor- tant in our natural defence against infection, and may well also initiate tissue repair by, for example, promoting fibroblast proliferation. ${ }^{40}$ Clearly this might be relevant in myocardial scar formation after an infarct.

The future for free radical modification in human heart disease is exciting, but the way forward must lie in careful identification and elucidation of free radical mechanisms in reperfusion injury in man. Only then should suitably controlled clinical trials proceed. We believe that the temptation to administer a theoretically harmless "anti-free radical" cocktail together with thrombolytic treatment for acute myocardial infarction is not yet justified.

\section{References}

1 Rutsch W, Schlutzler H. Intracoronary thrombolysis: organisational prerequisites, technique and results. Cardiovasc Intervent Radiol 1986;9:245-52.

2 Simoons ML, van der Brand $M$, de Zwaan C, et al. Improved survival after early thrombolysis in acute myocardial infarction. A randomized trial by the Interuniversity Cardiology Institute in the Netherlands. Lancet 1985;ii:578-81.

3 ISIS-2 (second International Study of Infarct Survival) Collaborative Group. Randomised trial of intravenous streptokinase, aspirin, both, or neither among 17187 cases of suspected acute myocardial infarction: ISIS-2. Lancet 1988;ii:349-60.

4 AIMS trial study group. Effect of intravenous APSAC on mortality after acute myocardial infarction: preliminary report of a placebo-controlled clinical trial. Lancet 1988;i:545-9.

5 Yusuf S, Collins R, Peto R, et al. Intravenous and intracoronary fibrinolytic therapy in acute myocardial infarction: overview of results on mortality, reinfarction and side effects from 33 controlled randomized trials. Eur Heart $J$ 1984;6:556-85.

6 Reimer KA, Jennings RB. The "wavefront phenomenon" of myocardial ischemic cell death. Lab Invest 1979;40:633-44.

7 Jennings RB, Sommers HM, Smyth GA, et al. Myocardial necrosis induced by temporary occlusion of a coronary artery in the dog. Arch Pathol 1960;70: 68-78.

8 Braunwald E, Kloner RA. Myocardial reperfusion: a double-edged sword. J Clin Invest 1985;76:1713-9.

9 Green MJ, Hill HAO. Chemistry of dioxygen. In: Packer L, ed. Methods in enzymology. New York: Academic Press, 1984;105:3-22.

10 Halliwell B. Superoxide dependent formation of hydroxyl radicals in the presence of iron chelates: is it a mechanism for hydroxyl radical.production in biochemical systems? FEBS Lett 1978;92:321-6.

11 Pryor WA. Oxy-radicals and related species: their (formation, lifetimes and reactions. Ann Rev Physiol 1986;48:657-67.

12 Sullivan JL. Sex, iron and heart disease [Letter]. Lancet 1986;ii:1162.

13 Weiss SJ, Lampert MB, Test ST. Long-lived oxidants 
generated by human neutrophils: characterisation and bioactivity. Science 1983;222:625-8.

14 McCord JM. Oxygen derived free radicals in postischemic injury. $N$ Engl J Med 1985;312:159-63.

15 Hearse DJ, Manning AS, Downey JM, Yellon DM. Xanthine oxidase: a critical mediator of myocardial injury during ischemia and reperfusion? Acta Physiol Scand 1986(suppl 548):65-78.

16 Engerson TD, McKelvey TG, Rhynie DB, et al. Conversion of xanthine dehydrogenase to oxidase in ischaemic rat tissue. J Clin Invest 1987;79:1564-70.

17 Freeman BA, Crapo JD. Biology of disease: free radicals and tissue injury. Lab Invest 1982;47:412-26.

18 Egan RW, Paxton J, Kuehl FA Jr. Mechanisms for the irreversible self deactivation of prostaglandin synthetase. J Biol Chem 1976;251:7329-35.

19 Biemond P, van Eijk HG, Swaak AJG, Koster JF. Iron mobilisation from ferritin by superoxide derived from stimulated polymorphonuclear leukocytes: possible mechanism in inflammatory diseases. J Clin Invest 1984;73:1576-9.

20 Blake DR, Allen RE, Lunec J. Free radicals in biological systems - a review orientated to the inflammatory process. Br Med Bull 1987;43:371-85.

21 Dormandy TL. An approach to free radicals. Lancet 1983;ii:101-4.

22 Gutteridge JMC, Quinlan GJ. Malondialdehyde formation from lipid peroxides in the thiobarbituric acid test: the role of lipid radicals, iron salts, and metal chelators. J Appl Biochem 1983;5:293-9.

23 Halliwell B, Gutteridge JMC. Lipid peroxidation, oxygen radicals, cell damage, and antioxidant therapy. Lancet 1984;i:1396-7.

24 Mason RP. Assay of in situ radicals by electron spin resonance. In: Packer L, ed. Methods in enzymology. New York: Academic Press, 1984;105:416-22.

25 Rao PS, Cohen MV, Mueller HS. Production of free radicals and lipid peroxides in early experimental myocardial ischaemia. J Mol Cell Cardiol 1983; 15:713-6.

26 Basu DK, Hagmaeyn M. Injury to rat hearts produced by an exogenous free radical generating system. Study into the role of arachidonic acid and eicosanoids. J Pharmacol Exp Ther 1987;242:673-85.

27 Ytrehus K, Myklebust R, Olsen R, Mjos OD. Ultrastructural changes induced in the isolated rat heart by enzymatically generated oxygen radicals. $\mathrm{J} \mathrm{Mol} \mathrm{Cell}$ Cardiol 1987;19:379-89.
28 Roth E, Torok B, Bar W, Pollak S. Antioxidant protection against free radical mediated myocardial injury. Prog Clin Biol Res 1987;236A:633-40.

29 Arnold WL, De Wall RA, Kezdi P, Zwart HHJ. The effect of allopurinol on the degree of early myocardial ischaemia. Am Heart J 1980;99:614-24.

30 De Wall RA, Vasko KA, Stanley E, Kezdi P. Responses of the myocardium to allopurinol. Am Heart $J$ 1971; 82:362-70.

31 Manning AS, Coltart DJ, Hearse DJ. Ischaemia and reperfusion-induced arrhythmias in the rat: effects of xanthine oxidase inhibition with allopurinol. Circ Res 1984;55:545-8.

32 Jolly SR, Kane WJ, Bailie MB, et al. Canine myocardial reperfusion injury: its reduction by the combined administration of superoxide dismutase and catalase. Circ Res 1984;54:277-85.

33 Przyklenk K, Kloner RA. Effect of oxygen-derived free radical scavengers on infarct size following six hours of permanent coronary artery occlusion: salvage or delay of myocyte necrosis? Basic Res Cardiol 1987; 82:146-58.

34 Nasuland U, Haggmark S, Johansson G, et al. Superoxide dismutase and catalase reduce infarct size in a porcine myocardial occlusion reperfusion model. $J$ Mol Cell Cardiol 1986;18:1072-84.

35 Gaudel Y, Duvelleroy MA. Role of oxygen radicals in cardiac injury due to reoxygenation. J Mol Cell Cardiol 1984;16:459-70.

36 Das DK, Engelman RM, Otani H, et al. Effect of superoxide dismutase and catalase on myocardial energy metabolism during ischaemia and reperfusion. Clin Physiol Biochem 1986;4:187-98.

37 Stewart JR, Blackwell WH, Crute SL, et al. Prevention of myocardial ischaemia/reperfusion injury with oxygen free radical scavengers. $J$ Thorac Cardiovasc Surg 1985;90:68-72.

38 Otani H, Engelman RM, Rousou JA, et al. Cardiac performance during reperfusion improved by pretreatment with oxygen free radical scavengers. $J$ Thorac Cardiovasc Surg 1986;91:290-5.

39 Myers ML, Bolli R, Lekich MS, et al. Enhancement of recovery of myocardial function by oxygen freeradical scavengers after reversible regional ischaemia. Lab Invest 1985;72:915-21.

40 Murrell GAC, Francis MJO, Bromley L. Free radicals and Dupuytren's contracture. Br Med J 1987; 295:1373-5. 